\title{
Penggunaan Angka Keterkaitan untuk Penentuan Tingkat Aksesibilitas Kota/Kabupaten di Wilayah Propinsi Kalimantan Barat
}

\author{
Djoko Sulistiono, Amalia Firdaus Mawardi, Ami Asparini, Endang Kasiati \\ Program Studi Diploma Teknik Sipil FTSP ITS, Surabaya \\ Email:djoko_sulistiono@ce.its.ac.id
}

\begin{abstract}
The road network has an important function in the transport system because it generate movement of goods and people. The performance of the road network should be measurable to support this important function. Performance of road network measured through the accessibility index and Mobility Index in accordance with the Minimum Service Standards (MSS) of the Department of Public Works. The problems that should be adressed includes what is the accessibility level of the city in the province of West Kalimantan and what is the priority of road network development in respect of the conditions of accessibility. The objective of this research was to determine the level of accessibility of the city in the province of West Kalimantan and the priority roads to improve accessibility in that city. Network analysis in the form of matrix table of shortest distance between cities/districts is presented. From this analysis the linkages number of the entire road network can then be determined. This study found that the priority handling to solve the accessibility issues are Putus Sibau (681 km), Ketapang $(681 \mathrm{~km})$, Sambas $(594 \mathrm{~km})$, Singkawang $(568 \mathrm{~km})$, Sukadana $(563 \mathrm{~km})$ and Mempawah $(556 \mathrm{~km})$.
\end{abstract}

Keywords: Accessibility Index, Mobility Index, accessibility level, number linkages.

Abstrak

Jaringan jalan mempunyai fungsi yang cukup penting dalam sistem transportasi, karena mampu menghasilkan pergerakan barang/orang, sehingga jaringan jalan tersebut harus bisa diukur kinerjanya untuk mendukung pergerakan orang/barang. Pengukuran kinerja jaringan jalan dapat dilakukan melalui Indeks Aksesibilitas dan Indeks Mobilitas yang sesuai dengan Standar Pelayanan Minimum (SPM) Departemen PU. Permasalahan yang mungkin terjadi antara lain adalah bagaimana tingkat aksesibilitas kota/kabupaten di wilayah Propinsi Kalimantan Barat dan bagaimana prioritas pembangunan jaringan jalan sehubungan kondisi aksesibilitas tersebut. Tujuan penelitian adalah mengetahui tingkat aksesibilitas kota/kabupaten di wilayah provinsi Kalimantan Barat dan prioritas pembangunan jalan untuk meningkatkan aksesibilitas di kota/kabupaten wilayah tersebut. Hasil analisa jaringan yang berupa matrix jarak tempuh terpendek antar kota/kabupaten, kemudian ditentukan angka keterkaitan seluruh jaringan jalan. Angka keterkaitan setiap kota/kabupaten dicari rataratanya, kemudian dinilai tingkat aksesibilitas masing-masing kota/kabupaten, apabila angka keterkaitan kota/kabupaten diatas rata-ratanya, maka tingkat aksesibilitasnya rata-rata rendah, demikian sebaliknya. Hasil analisa angka keterkaitan didapatkan angka keterkaitan rata-rata $531 \mathrm{~km}$, sehingga bila angka keterkaitan/kabupaten yang lebih besar dari rataratanya, maka kota/kabupaten tersebut mempunyai aksesibilitas rendah. Urutan prioritas pananganan untuk mengatasi masalah aksesibilitas ini adalah Putus Sibau $(681 \mathrm{~km})$, Ketapang $(681 \mathrm{~km})$, Sambas $(594 \mathrm{~km})$, Singkawang $(568 \mathrm{~km})$, Sukadana $(563 \mathrm{~km})$, dan Mempawah $(556$ km).

Kata kunci: Indeks Aksesibilitas, Indeks Mobilitas, tingkat aksesibilitas, angka keterkaitan.

\section{Pendahuluan}

Kalimantan Barat merupakan provinsi yang cukup besar, karena provinsi dengan luas $146.807 \mathrm{~km}^{2}$ tersebut mempunyai urutan terbesar ke empat dari provinsi yang ada di Indonesia. Panjang jalan di Provinsi Kalimantan Barat adalah $10.494 \mathrm{~km}$, yang menghubungkan ibu kota Provinsi (Pontianak), Kota pantai (Singkawang) dan 12 
ibu kota kabupaten lainnya. Kotamadya/Kabupaten sebagai pusat zona, ruas jalan sebagai link dan pertemuan ruas jalan sebagai node. Provinsi ini dilalui sungai besar Kapuas sepanjang 1.143 $\mathrm{km}$ dan termasuk sungai terpanjang di Indonesia. Jumlah penduduk sesuai data sensus tahun 2004 sebanyak 4.073.304 jiwa dan pada tahun 2005 mencapai 4.734.373 jiwa. Potensi wilayah yang merupakan unggulan Kalimantan Barat adalah karet, kelapa sawit, dan kayu lapis, yang mampu memberikan kontribusi terhadap pengembangan wilayah dan PDB Pulau Kalimantan.

Menurut Mawardi (2013), Provinsi Kalimantan Barat mempunyai Indeks Aksesbilitas jaringan sebesar 0,071 > 0,05 (persyaratan), Indeks Mobilitas sebesar 0,0022 $<0,005$ (persyaratan), sehingga masih mempunyai persoalan dengan mobilitas. Kemudian dengan metode pohon bangunan, kota yang mempunyai aksesibilitas paling baik adalah Kota Ngabang (2763 km), sedang kota kabupaten dengan aksesibilitas kabupaten dengan paling jelek adalah Kota Putus Sibau (6092 km).

Potensi wilayah yang cukup besar dan kondisi jaringan jalan yang kurang baik memerlukan penyelesaian dalam bentuk pembangunan/peningkatan jalan. Permasalahan, bagaimana tingkat aksesibilitas kota/kabupaten di wilayah Provinsi Kalimantan Barat? Bagaimana prioritas pembangunan jaringan jalan sehubungan kondisi aksesibilitas tersebut? Tujuan penelitian adalah mengetahui tingkat aksesibilitas kota/kabupaten di wilayah provinsi Kalimantan
Barat dan prioritas pembangunan jalan untuk meningkatkan aksesibilitas di kota/kabupaten wilayah tersebut.

\section{Metodologi}

Tingkat aksesibilitas suatu wilayah kota/kabupaten dapat ditentukan berdasarkan matrix jarak tempuh terpendek antar kota/kabupaten pada wilayah propinsi tersebut. Menurut ketentuan Ditjen Perhubungan Darat, Departemen Perhubungan (1995), melalui matrix tersebut dapat ditentukan angka keterkaitan setiap wilayah kota/kabupaten, yang kemudian dicari rata-ratanya. Angka keterkaitan suatu kota/kabupaten yang lebih besar dari angka keterkaitan rata-rata, maka dapat dikatakan kota/kabupaten tersebut mempunyai aksesibilitas yang rendah. Kota/kabupaten yang rendah aksesibilitasnya, perlu ditingkatkan aksesibilitasnya melalui pembangunan jalan ke lokasi tersebut. Urutan prioritas pembangunan jalan didasarkan pada angka keterkaitan setiap kota/kabupaten, nilai angka keterkaitan yang besar akan mendapat prioritas pertama, demikian untuk prioritas selanjutnya.

\section{Hasil dan Pembahasan}

Data jaringan jalan di wilayah Kalimantan Barat, terutama data panjang ruas jalan $(\mathrm{km})$, Lihat Gambar 1. Data tentang kondisi perkerasan jalan belum dapat diperoleh pada saat ini, sehingga karakteristik ruas jalan menggunakan panjang jalan $(\mathrm{km})$, bukan waktu tempuh (jam) pada ruas jalan tersebut. Hasil analisa jaringan jalan menurut Mawardi 
(2013), sesuai Standar Pelayanan Minimal (SPM) Departemen PU diperoleh Indeks Aksesibilitas sebesar 0,071>0,05 (memenuhi persyaratan) dan Indeks Mobilitas sebesar 0,0022 < 0,005 (belum memenuhi persyaratan), sehingga kondisi jaringan jalan di Propinsi Kalimantan Barat masih bermasalah dari sisi mobilitas. Perhitungan jarak dari pusat zona ibukota provinsi/kabupaten ke pusat zona ibu kota kabupaten lainnya, dengan menggunakan metode lintasan terpendek $(\mathrm{km})$ atau metode pohon bangunan (tree building). Hasi perhitungan menurut Mawardi (2013), lihat Tabel 1.

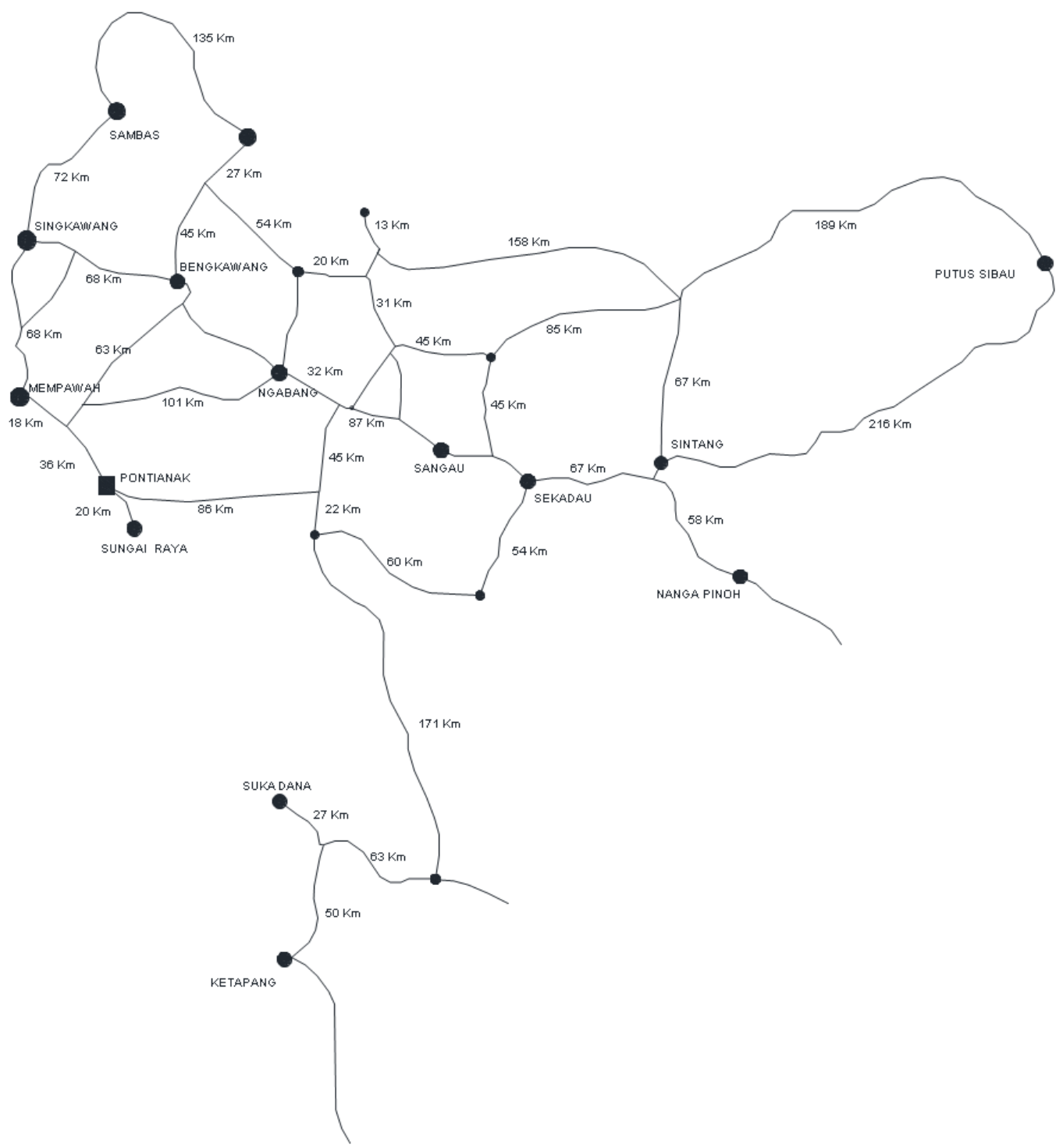

Gambar 1. Jaringan Jalan di Wilayah Kalimantan Barat (Mawardi, 2013) 
Tabel 1. Lintasan terpendek $(\mathrm{km})$ antar kota/kabupaten di wilayah Provinsi Kalimantan Barat

\begin{tabular}{|c|c|c|c|c|c|c|c|c|c|c|c|c|c|c|c|c|}
\hline $\begin{array}{l}\mathrm{N} \\
\mathrm{o}\end{array}$ & Nama Kota & 1 & 2 & 3 & 4 & 5 & 6 & 7 & 8 & 9 & 10 & 11 & 12 & 13 & 14 & $\begin{array}{l}\text { Total } \\
(\mathrm{km})\end{array}$ \\
\hline 1 & Pontianak & - & 54 & 137 & 218 & 222 & 289 & 347 & 505 & 369 & 392 & 122 & 194 & 99 & 20 & 2968 \\
\hline 2 & Memdawah & 54 & - & 119 & 238 & 273 & 340 & 398 & 556 & 423 & 446 & 68 & 140 & 81 & 74 & 3210 \\
\hline 3 & Ngabang & 137 & 119 & - & 119 & 154 & 221 & 279 & 437 & 360 & 383 & 131 & 203 & 63 & 157 & 2763 \\
\hline 4 & Sanggau & 218 & 238 & 119 & - & 35 & 102 & 160 & 318 & 410 & 433 & 250 & 322 & 182 & 238 & 3025 \\
\hline 5 & Sekadau & 222 & 273 & 154 & 35 & - & 67 & 125 & 283 & 375 & 398 & 285 & 357 & 217 & 242 & 3033 \\
\hline 6 & Sintang & 289 & 340 & 221 & 102 & 67 & - & 58 & 216 & 442 & 465 & 352 & 424 & 284 & 309 & 3569 \\
\hline 7 & Nangapinoh & 347 & 398 & 279 & 160 & 125 & 58 & - & 274 & 500 & 523 & 410 & 482 & 342 & 367 & 4265 \\
\hline 8 & PutusSibau & 505 & 556 & 437 & 318 & 283 & 216 & 274 & - & 658 & 681 & 568 & 594 & 477 & 525 & 6092 \\
\hline 9 & Sukadana & 369 & 423 & 360 & 410 & 375 & 442 & 500 & 658 & - & 77 & 491 & 563 & 468 & 389 & 5525 \\
\hline 10 & Katapang & 392 & 446 & 383 & 433 & 398 & 465 & 523 & 681 & 77 & - & 514 & 586 & 509 & 412 & 5819 \\
\hline 11 & Singkanang & 122 & 68 & 131 & 250 & 285 & 352 & 410 & 568 & 491 & 514 & - & 72 & 68 & 142 & 3473 \\
\hline 12 & Sambas & 194 & 140 & 203 & 322 & 357 & 424 & 482 & 594 & 563 & 586 & 72 & - & 140 & 214 & 4291 \\
\hline 14 & Bengkayang & 99 & 81 & 63 & 182 & 217 & 284 & 342 & 477 & 468 & 509 & 68 & 140 & - & 119 & 3049 \\
\hline 14 & Sungai Raya & 20 & 74 & 157 & 238 & 242 & 309 & 367 & 525 & 389 & 412 & 142 & 214 & 119 & - & 3208 \\
\hline & Total $(\mathrm{km})$ & 2968 & 3210 & 2763 & 3025 & 3033 & 3569 & 4265 & 6092 & 5525 & 5819 & 3473 & 4291 & 3049 & 3208 & - \\
\hline
\end{tabular}

Sumber: Mawardi, 2013.

Sesuai Tabel 1, dapat ditentukan angka keterkaitan kota/kabupaten di wilayah Propinsi Kalimantan Barat dengan hasil sebagaimana Tabel 2.

Kemudian angka keterkaitan masingmasing kota/kabupaten sesuai Tabel 2 dicari rata-ratanya, diperoleh angka keterkaitan rata-rata sebesar $531 \mathrm{~km}$.
Kota/kabupaten yang mempunyai angka keterkaitan diatas angka keterkaitan rata-rata, dapat dikatakan mempunyai aksesibilitas yang rendah. Secara prioritas dan sesuai angka keterkaitannya diperoleh urutan prioritas untuk peningkatan aksesibilitasnya sebagaimana Tabel 3.

Tabel 2. Angka keterkaitan kota/kabupaten di wilayah Provinsi Kalimantan Barat

\begin{tabular}{cccc}
\hline No. & Nama Kota/Kabupaten & Angka Keterkaitan terbesar $(\mathrm{km})$ & Keterangan \\
\hline 1 & Pontianak & 505 & < rata-rata \\
2 & Memdawah & 556 & > rata-rata \\
3 & Ngabang & 437 & < rata-rata \\
4 & Sanggau & 433 & < rata-rata \\
5 & Sekadau & 398 & < rata-rata \\
6 & Sintang & 465 & < rata-rata \\
7 & Nangapinoh & 523 & < rata-rata \\
8 & PutusSibau & 681 & > rata-rata \\
9 & Sukadana & 563 & $>$ rata-rata \\
10 & Katapang & 681 & $>$ rata-rata \\
11 & Singkanang & 568 & $>$ rata-rata \\
12 & Sambas & 594 & $>$ rata-rata \\
13 & Bengkayang & 509 & < rata-rata \\
14 & Sungai Raya & 525 & $>$ rata-rata \\
\hline
\end{tabular}

Sumber: Mawardi, 2013. 
Tabel 3. Prioritas Pembangunan Jalan ke Kota/Kabupaten

\begin{tabular}{ccccc}
\hline No. & Nama Kota/Kabupaten & Angka Keterkaitan terbesar $(\mathrm{km})$ & Prioritas & Keterangan \\
\hline 1 & Putus Sibau & 681 & 1 & Aksesbilitas rendah \\
2 & Ketapang & 681 & 2 & Aksesbilitas rendah \\
3 & Sambas & 594 & 3 & Aksesbilitas rendah \\
4 & Singkawang & 568 & 4 & Aksesbilitas rendah \\
5 & Sukadana & 563 & 5 & Aksesbilitas rendah \\
6 & Mempawah & 556 & 6 & Aksesbilitas rendah \\
7 & Sungai Raya & 525 & 7 & Aksesbilitas tinggi \\
8 & Nangapinoh & 523 & 8 & Aksesbilitas tinggi \\
9 & Bengkayang & 509 & 9 & Aksesbilitas tinggi \\
10 & Pontianak & 505 & 10 & Aksesbilitas tinggi \\
11 & Sintang & 465 & 11 & Aksesbilitas tinggi \\
12 & Ngabang & 437 & 12 & Aksesbilitas tinggi \\
13 & Sanggau & 433 & 13 & Aksesbilitas tinggi \\
14 & Sekadau & 398 & 14 & Aksesbilitas tinggi \\
\hline
\end{tabular}

Sumber: hasil analisa

Kota/kabupaten tingkat aksesibilitas yang rendah ini memerlukan tambahan akses berupa jalan baru yang mampu memperpendek lintasan yang telah ada. Konstruksi perkerasan jalan yang cocok untuk wilayah pedalaman menurut Sulistiono (2013) cukup setingkat JAPAT, atau Jalan Agregat Padat Tahan Cuaca sesuai standar Departemen PU. Perkerasan Japat merupakan perkerasan yang optimum pada biaya yang minimum, sehingga panjang jangkauan $(\mathrm{km})$ bisa lebih luas, lihat Gambar 2 dan 3.

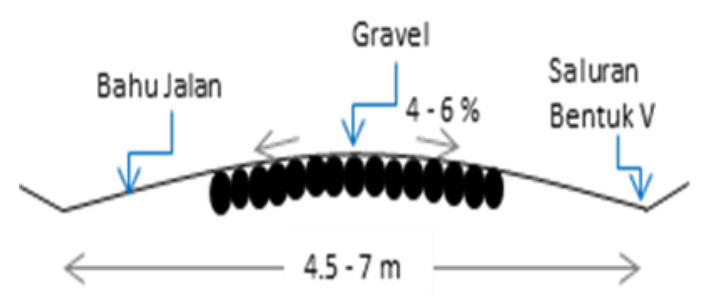

Gambar 2. Potongan melintang JAPAT (Sulistiono, 2013).

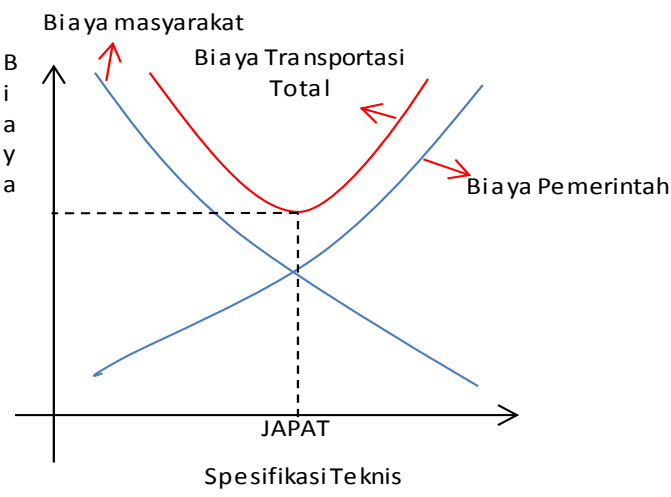

Gambar 3. Hubungan Spesifikasi Teknis dengan Biaya Total (Sulistiono, 2013).

\section{Simpulan}

Sesuai hasil pembahasan diperoleh Indeks Aksesbilitas jaringan sebesar 0,071>0,05 (memenuhi persyaratan) dan Indeks Mobilitas sebesar 0,0022 < 0,005 (belum memenuhi persyaratan), yang artinya masih diperlukan tambahan ruas jalan untuk meningkatkan Indeks Mobilitas agar memenuhi persyaratan. Kemudian sesuai dengan hasil perhitungan lintasan terpendek sebagaimana pada matrix, maka Kota kabu- 
paten dengan aksesbilitas yang baik adalah kota Ngabang $(2.763 \mathrm{~km})$, sedang kota Kabupaten dengan aksesbilitas paling jelek adalah kota Putus Sibau $(6.092 \mathrm{~km}$ atau total aksesbilitas ke 13 kota kabupaten lainnya adalah $6.092 \mathrm{~km}$ ). Hasil ini diperkuat dengan penggunaan angka keterkaitan dalam penentuan tingkat aksesbilitas dan prioritas pembangunan jalan, dimana Putus Sibau $(681 \mathrm{~km})$ mendapat prioritas pertama pembangunan jalan ke lokasi tersebut, disusul kota lainnya seperti Ketapang (681 km), Sambas (594 km), Singkawang $(568 \mathrm{~km})$, Sukadana $(563 \mathrm{~km})$ dan Mempawah $(556 \mathrm{~km})$ dan seterusnya. Pembangunan jalan baru cukup dengan konstruksi JAPAT (jalan Agregate Padat Tahan Cuaca) sesuai standar Departemen PU.

\section{Daftar Pustaka}

Abubakar, Iskandar, A. Yani, dan Edi S., (1993). Manuju Lalu Lintas adan Angkutan Jalan yang Tertib. Dirjen Perhubungan Darat Departemen Perhubungan.

Departemen Pekerjaan umum. (1983). Petunjuk Pelaksanaan Jalan Agregate Padat Tahan Cuac (JAPAT).

Mawardi A., Djoko Sulistiono, Ami Asparini. (2013). Kinerja jaringan jalan dalam upaya mendukung pergerakan orang/barang di wilayah propinsi Kalimantan Barat. Prosiding Seminar Nasional ATPW 2013 Program Diploma Teknik Sipil FTSP ITS.

Morlok, Edward K., (1978). Introduction to transportation engineering. Prentice Hall International Inc.
Sulistiono, Djoko dan Amalia FM, Ami Asparini. (2013). Perawatan Jalan Agregate Padat Tahan Cuaca (JAPAT) untuk menunjang aksesibilitas di wilayah pedalaman. Prosiding Seminar Nasional ATPW2013 Program Diploma Teknik Sipil FTSP ITS. 